\title{
Rapid Evaluation of the Pozzolanic Activity of Bayer Red Mud by a Polymerization Degree Method: Correlations with Alkali Dissolution of $(\mathrm{Si}+\mathrm{Al})$ and Strength
}

\author{
Yaguang Wang ${ }^{1,2}$, Xiaoming Liu ${ }^{1,2, *}$, Zhiqing Xie ${ }^{2}$, Huimin Wang ${ }^{2}$, Wei Zhang ${ }^{2}$ and Yang Xue ${ }^{2}$ \\ 1 State Key Laboratory of Advanced Metallurgy, University of Science and Technology Beijing, \\ Beijing 100083, China; wangyg@xs.ustb.edu.cn \\ 2 School of Metallurgical and Ecological Engineering, University of Science and Technology Beijing, \\ Beijing 100083, China; xiezhiqing8023@163.com (Z.X.); 41802169@xs.ustb.edu.cn (H.W.); \\ b20190124@xs.ustb.edu.cn (W.Z.); cdxueyang@163.com (Y.X.) \\ * Correspondence: liuxm@ustb.edu.cn
}

check for updates

Citation: Wang, Y.; Liu, X.; Xie, Z.; Wang, H.; Zhang, W.; Xue, Y. Rapid Evaluation of the Pozzolanic Activity of Bayer Red Mud by a

Polymerization Degree Method: Correlations with Alkali Dissolution of ( $\mathrm{Si}+\mathrm{Al})$ and Strength. Materials 2021, 14, 5546. https://doi.org/ $10.3390 /$ ma14195546

Academic Editor: Paola Palmero

Received: 10 September 2021

Accepted: 20 September 2021

Published: 24 September 2021

Publisher's Note: MDPI stays neutral with regard to jurisdictional claims in published maps and institutional affiliations.

Copyright: (c) 2021 by the authors. Licensee MDPI, Basel, Switzerland. This article is an open access article distributed under the terms and conditions of the Creative Commons Attribution (CC BY) license (https:/ / creativecommons.org/licenses/by/ $4.0 /)$.

\begin{abstract}
A large amount of Bayer process red mud is discharged in the process of alumina production, which has caused significant pollution in the environment. The pozzolanic activity of Bayer red mud as a supplementary cementitious material is a research hotspot. In this work, a new method for Fourier-transform infrared spectrometry is used to determine the polymerization degree of Bayer red mud in order to evaluate its pozzolanic activity. Based on the results of the dissolution concentration of $(\mathrm{Si}+\mathrm{Al})$, strength index and polymerization degree of Bayer red mud, the relationships between different evaluation methods were analyzed, and the relevant calculation formulas of pozzolanic activity were obtained. The results showed that different evaluation methods can reflect the variation law of pozzolanic activity in Bayer red mud. The polymerization degree of Bayer red mud had a good linear relationship with the pozzolanic activity index obtained by the strength index and dissolution concentration of $(\mathrm{Si}+\mathrm{Al})$, respectively. The polymerization degree was negatively correlated with pozzolanic activity index and dissolution concentration of $(\mathrm{Si}+\mathrm{Al})$, and the correlation coefficients were greater than 0.85 . Therefore, this method was found to be effective and hence can be used as a rapid and simple test for pozzolanic activity evaluation of Bayer red mud.
\end{abstract}

Keywords: Bayer red mud; pozzolanic activity; evaluation method; polymerization degree; dissolution of $(\mathrm{Si}+\mathrm{Al})$

\section{Introduction}

Bayer red mud (RM) is a kind of strong alkaline solid waste discharged in the process of alumina production; about 1-2 tons of RM will be discharged per ton of alumina production [1-3]. At present, the annual discharge of RM has exceeded 100 million tons in China, which is mainly disposed of by damming, and the comprehensive utilization rate is less than 4\% [3]; this stacked RM has caused serious pollution to the surrounding environment. In order to solve the problem of RM pollution, the comprehensive utilization of RM has become a focus for researchers.

Meanwhile, increases in infrastructure worldwide have led to a substantial increase in the demand for cement. However, cement production not only consumes a large amount of coal, limestone, iron ore, clay and other resources, but also discharges a large amount of $\mathrm{CO}_{2}$, which seriously pollutes the environment. The green sustainable development of cement has been a concern of international scholars, and research focus has mainly been on energy conservation, emission reduction and environmental protection, in order to meet the needs of carbon neutrality. Industrial solid wastes, such as fly ash, and blast furnace and steel slag, have been widely used as supplementary cementitious materials in the field of cement and concrete [4-6]. 
RM can be used as a supplementary cementitious material for cement and concrete, which can greatly improve the resource utilization rate of RM. However, the current utilization rate of RM in cementitious materials is low because of its high alkalinity and low pozzolanic activity [3]. The pozzolanic activity of industrial solid waste is a hot topic in current research [7]. Some methods for evaluating pozzolanic reactivity were proposed based on the principle of interactions between calcium hydroxide and industrial solid waste with potential pozzolanic activity. Moreover, some simple, rapid and quantitative methods have been used to evaluate the pozzolanic activity of industrial solid waste; these methods include the chemical composition of industrial solid waste, crystallinity of minerals, and strength and electrochemical performance [8-12]. In addition, although strength evaluation can comprehensively and intuitively reflect the overall pozzolanic activity of materials, the required cycle is usually long. The dissolution evaluation must select appropriate conditions to separate the active components from the inert components. However, there are many influencing factors in the implementation of this method, such as the type, concentration, and dissolution time and temperature of alkali solutions, which will lead to large errors in the experimental results. In recent years, some scholars have studied new methods for testing the pozzolanic activity of materials. Martín et al. [13] measured the pozzolanic activity of hollow glass microspheres through the improved Chapelle test and compared the compressive strength of hardened cement paste samples, and were able to obtain better results. Basto et al. [14]. studied the pozzolanic activity of sewage sludge ash via a conductivity method. The results show that there is a good correlation between mortar compressive strength tests and conductivity tests. Hasani et al. [15]. proposed a new method to simply compare pozzolanic activities by using the molecular dynamics simulation method. The adsorption process of water molecules on the surface of pozzolanic minerals was simulated, and the water/surface interaction energy was used as a criterion for investigating mineral activity. However, the physical and chemical properties of different kinds of industrial solid wastes are greatly different, which leads to difficulties in establishing a model that accurately evaluates the pozzolanic activity of industrial solid wastes. It is worth noting that there are many factors affecting the pozzolanic activity of RM. Therefore, it is of great importance to find a quick and effective method for determining the pozzolanic activity of RM.

In this work, the evaluation of pozzolanic activity of RM by polymerization degree was proposed. The pozzolanic activity of calcined RM at different temperatures was evaluated by the methods of strength, dissolution of $(\mathrm{Si}+\mathrm{Al})$ and polymerization degree. The polymerization degree of RM was characterized by FTIR. Correlations between polymerization degree and other evaluation methods of pozzolanic activity were established, providing a theoretical reference for the application of RM in the field of cement and concrete.

\section{Materials and Methods}

RM was produced by the China Aluminum Co., Ltd. Shanxi Branch, Hejin, China. Cement (42.5) was purchased from the Tangshan Jidong Cement Co., Ltd, Tangshan, China. Standard sand was purchased from a factory in Henan, China. Sodium hydroxide was purchased from Sinopharm Chemical Reagent Co., Ltd, Beijing, China. Deionized water was made in the laboratory. An XRF was used to analyze the main chemical constituents of RM and cement. The main chemical constituents of RM and cement are shown in Table 1. The main chemical constituents of $\mathrm{RM}$ are $\mathrm{Fe}_{2} \mathrm{O}_{3}, \mathrm{Al}_{2} \mathrm{O}_{3}, \mathrm{SiO}_{2}, \mathrm{Na}_{2} \mathrm{O}$ and a small amount of $\mathrm{CaO}$.

Table 1. The chemical constituents of RM and cement (wt.\%).

\begin{tabular}{cccccccccc}
\hline Oxides & $\mathrm{SiO}_{\mathbf{2}}$ & $\mathrm{Al}_{\mathbf{2}} \mathrm{O}_{\mathbf{3}}$ & $\mathrm{Fe}_{\mathbf{2}} \mathrm{O}_{3}$ & $\mathrm{CaO}$ & $\mathbf{M g O}$ & $\mathrm{Na}_{\mathbf{2}} \mathrm{O}$ & $\mathrm{SO}_{3}$ & $\mathrm{TiO}_{2}$ & $\mathrm{LOI}$ \\
\hline $\mathrm{RM}$ & 22.71 & 22.96 & 26.57 & 2.17 & 0.13 & 11.08 & 1.01 & 1.72 & 11.19 \\
Cement & 18.60 & 3.81 & 3.25 & 64.86 & 2.90 & 0.24 & 0.45 & 0.31 & 4.14 \\
\hline
\end{tabular}


First, $200 \mathrm{~g}$ of $\mathrm{RM}$ was weighed and put into a muffle furnace $(\triangle \mathrm{S} 1200$, Zhengzhou Ansheng Scientific Instrument Co., Ltd, Zhengzhou, China). The muffle furnace was heated to a set temperature at a rate of $10{ }^{\circ} \mathrm{C} / \mathrm{min}$ (the set temperatures were $100{ }^{\circ} \mathrm{C}$, $200{ }^{\circ} \mathrm{C}, 300{ }^{\circ} \mathrm{C}, 400{ }^{\circ} \mathrm{C}, 500{ }^{\circ} \mathrm{C}, 600^{\circ} \mathrm{C}, 700{ }^{\circ} \mathrm{C}, 800{ }^{\circ} \mathrm{C}, 900{ }^{\circ} \mathrm{C}$ and $1000{ }^{\circ} \mathrm{C}$, respectively). After reaching the set temperature, the muffle furnace was kept warm for $2 \mathrm{~h}$. After calcination, the RM was cooled to room temperature, and the RMs showing differing pozzolanic activities were obtained; the RMs were named RMn $(n=100-1000)$ for different calcination temperatures. Finally, the pozzolanic activity of RM was evaluated according to different experimental methods.

Strength method: The pozzolanic activity index of RM was calculated according to the Chinese standard GB/T 2847-2005 (pozzolanic materials used for cement production) [16]. The masses of RMs with different pozzolanic activities, the cement and the standard sand were $135 \mathrm{~g}, 315 \mathrm{~g}$ and $1350 \mathrm{~g}$, respectively; these were stirred and mixed according to a water-cement ratio of 0.5 , and then injected into an abrasive tool to vibrate and form. The prepared mortar sample was put into the curing box (YH-40B, Hebei Ruiheng test instrument factory, Cangzhou, China), the formwork removed after curing for $24 \mathrm{~h}$, and curing continued until 28 days. The curing temperature was $20 \pm 1{ }^{\circ} \mathrm{C}$, and the curing humidity was $95 \%$. The compressive strength of the sample was tested with the press (DYE-300, Beijing hengying Technology Co., Ltd, Beijing, China), with 6 test samples for each sample. The pozzolanic activity index $(\mathrm{K} \alpha)$ of RM was expressed by the compressive strength percentage of sample A (RM and cement system) at 28 days and sample B (cement system) at 28 days:

$\mathrm{K} \alpha=($ compressive strength of sample $\mathrm{A}) /($ compressive strength of sample $\mathrm{B}) \times 100 \%$

Alkali dissolution of $(\mathrm{Si}+\mathrm{Al})$ method: One gram of RMs with differing pozzolanic activities were taken and put into a $100 \mathrm{~mL}$ plastic bottle with $1 \mathrm{~mol} / \mathrm{L}$ of $\mathrm{NaOH}$ solution. After sealing, it was put into a curing room at $20^{\circ} \mathrm{C}$ for 7 days before filtering. The filtrate was sealed and stored in a plastic bottle. The contents of $\mathrm{Si}^{4+}$ and $\mathrm{Al}^{3+}$ in the filtrate were tested by ICP-OES (ICPOES730, Agilent Technologies, Palo Alto, CA, USA) [17]. It is worth noting that the more silicon and aluminum ions that were dissolved, the higher the pozzolanic activity of the RM.

Polymerization degree method: Origin software (Origin 2018, OriginLab, Northampton, MA, USA) was used to split and fit the peak area of $\mathrm{Si}(\mathrm{Al}) \mathrm{Q}^{\mathrm{n}}$ in the range of $800-1200 \mathrm{~cm}^{-1}$ on the FTIR spectrum. Zhang et al. [18] proposed the concept of the relative bridging oxygen bond (RBO) to evaluate the polymerization degree of $\left[\mathrm{SiO}_{4}\right]$. The polymerization degree was calculated by the following formula:

$$
\mathrm{RBO}=\frac{1}{4}\left(1 \times \frac{Q^{1}}{\Sigma Q^{\mathrm{n}}}+2 \times \frac{Q^{2}}{\Sigma Q^{\mathrm{n}}}+3 \times \frac{Q^{3}}{\Sigma Q^{\mathrm{n}}}+4 \times \frac{Q^{4}}{\Sigma Q^{\mathrm{n}}}\right)=\frac{1}{4} \times \frac{\Sigma \mathrm{n} \times Q^{\mathrm{n}}}{\Sigma Q^{\mathrm{n}}}
$$

The main chemical compositions of RM and cement were analyzed by X-ray fluorescence spectrometry (XRF; xrf-1700, Shimadzu, Shimadzu enterprise management (China) Co., Ltd, Shanghai, China). The phase composition of RM and cementitious materials was measured by an X-ray diffractometer (XRD; D/max Rb, Rigaku Corporation, Tokyo, Japan). The experimental conditions were $40 \mathrm{kV}, 100 \mathrm{~mA}$, Cu Target and scanning speed of $4 \% \mathrm{~min}$. The molecular bonds of the samples were tested by Fourier-transform infrared spectrometry (Nicolet IS10, Thermo Nicolet Corporation, Madison, GA, USA). The test conditions were as follows: sample and $\mathrm{KBr}$ were put into a mortar, ground and mixed evenly (1 mg of sample and $100 \mathrm{mg}$ of $\mathrm{KBr}$ ). After that, it was pressed into a transparent sheet of a specified size, and the measured wavenumber range was $400-4000 \mathrm{~cm}^{-1}$.

\section{Results and Discussion}

\subsection{XRD of RMs with Different Pozzolanic Activities}

The phase composition has an important influence on the pozzolanic activity of RM. Previous studies have shown that the amorphous phase is the most active phase in 
supplementary cementitious materials, such as GGBFS and fly ash [3]. The XRD patterns of RM calcined at different temperatures, as shown in Figure 1. It can be seen from Figure 1 (RM100) that the diffraction peaks of different phases in RM are clear and sharp, which indicates that there are few amorphous phase substances in RM, and that the crystallization degree of each phase is high. The phase analysis of RM shows that its main phase composition is composed of katoite, cancrinite, calcite, paragonite and diaspore. It is worth noting that the XRD patterns of RM100 and RM200 are similar, the XRD patterns of RM300-700 are similar, and the XRD patterns of RM800-1000 are similar. This shows that the phase composition of RM changes gradually with increases in temperature.
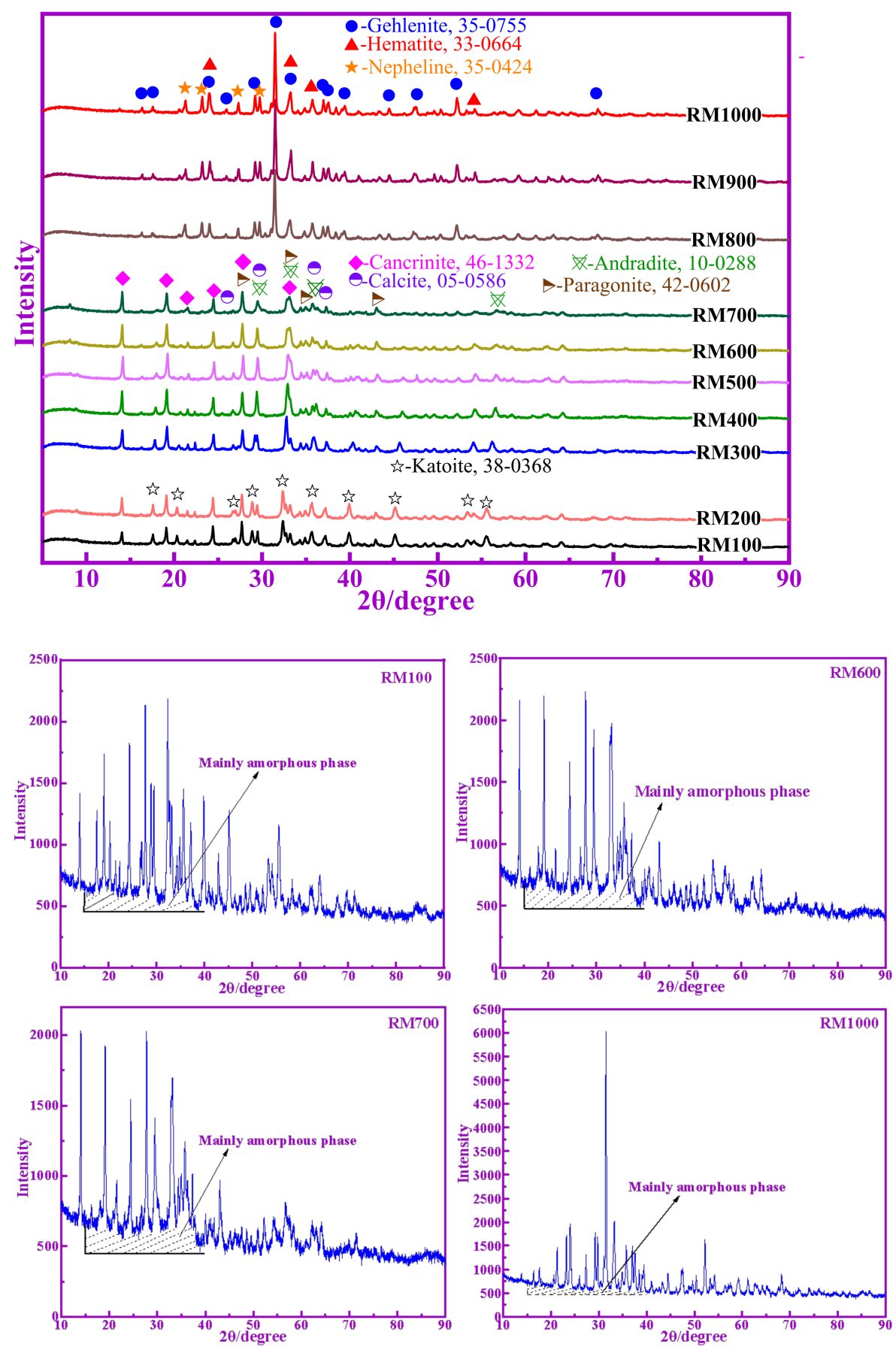

Figure 1. XRD patterns of calcined RM at different temperatures. 
In the XRD patterns of RM calcined at $\geq 300{ }^{\circ} \mathrm{C}$, the diffraction peaks for diaspore gradually disappear, which indicates that the diaspore has been decomposed-but no crystal peaks of $\mathrm{Al}_{2} \mathrm{O}_{3}$ have been found, indicating that the diaspore has decomposed to produce active $\mathrm{Al}_{2} \mathrm{O}_{3}$, which is difficult to detect in XRD [19]. At $300-700{ }^{\circ} \mathrm{C}$, katoite in RM begins to decompose hydroxyl and to transform into cancrinite. When the temperature rises to $700{ }^{\circ} \mathrm{C}$, the diffraction peak of katonite disappears completely. At the same time, the peak of calcite also decreased gradually, indicating that it also decomposed.

The phase composition of RM800-1000 is mainly composed of gehlenite, hamatite and nepheline. It is worth noting that these are newly formed substances. This shows that the original substances in RM have undergone phase transformation. After $800{ }^{\circ} \mathrm{C}$, the higher the temperature, the stronger the peak of crystalline phase in RM, indicating that the content of crystalline minerals in RM is relatively increased.

In addition, it can be seen from Figure 1 showing RM100, RM600, RM700 and RM1000, that the content of the amorphous phase in calcined RM at different temperatures is different. The content of the amorphous phase in RM700 is the highest and that in RM1000 is the lowest. This means that calcined RM has different pozzolanic activities at different temperatures.

The phase transformation reactions of RM during calcination at different temperatures are as follows:

$200-700{ }^{\circ} \mathrm{C}:$

$$
\mathrm{AlO}(\mathrm{OH}) \rightarrow \mathrm{Al}_{2} \mathrm{O}_{3}+\mathrm{H}_{2} \mathrm{O}
$$

Aluminosilicate minerals $\rightarrow$ Active silicon and aluminum

$$
\mathrm{CaCO}_{3} \rightarrow \mathrm{CaO}+\mathrm{CO}_{2}
$$

$800-1000{ }^{\circ} \mathrm{C}:$

$$
\mathrm{CaCO}_{3} \rightarrow \mathrm{CaO}+\mathrm{CO}_{2}
$$

Active silicon and aluminum $\rightarrow$ Aluminosilicate minerals

$$
\mathrm{CaO}+\mathrm{Al}_{2} \mathrm{O}_{3}+\mathrm{SiO}_{2} \rightarrow \text { Gehlenite }
$$

\subsection{Compressive Strength Evaluation of Pozzolanic Activity}

The compressive strength of RM and cement mortar is used as an index to evaluate pozzolanic activity. The compressive strength of mortar is a comprehensive index reflecting its structure; it can not only reflect the secondary reaction of RM in the hardening process, but can also reflect its filling water reduction effects. Therefore, the compressive strength test can comprehensively reflect the role of pozzolanic materials in the whole system.

Figure 2 shows the compressive strength of cement paste of calcined RM at different temperatures at 28 days. It can be seen from Figure 2 that the compressive strength of calcined RM mortar at different temperatures first increases and then decreases with temperature. The compressive strength of RM700 is the highest, reaching $48.52 \mathrm{MPa}$. Table 2 shows the pozzolanic activity index of calcined RM at different temperatures (he compressive strength of the standard cement mortar used is $62.80 \mathrm{MPa}$ at 28 days). It can be seen from Table 2 that the change law of the pozzolanic activity index of calcined RM at different temperatures is consistent with that of its compressive strength. This indicates that RM700 has the highest activity of $\mathrm{Si}$ and $\mathrm{Al}$, which is consistent with the area of amorphous peak in XRD. The compressive strength of RM1000 decreased significantly, and its compressive strength at 28 days was lower than that of RM100. The compressive strength and pozzolanic activity index of RM1000 were the lowest, indicating that the content of active $\mathrm{Si}$ and $\mathrm{Al}$ were the lowest, basically not participating in the hydration reaction, and mainly playing a filling role. The above results show that the pozzolanic activity of RM changes distinctly at different calcination temperatures, and that the pozzolanic activity of RM700 is the highest. 


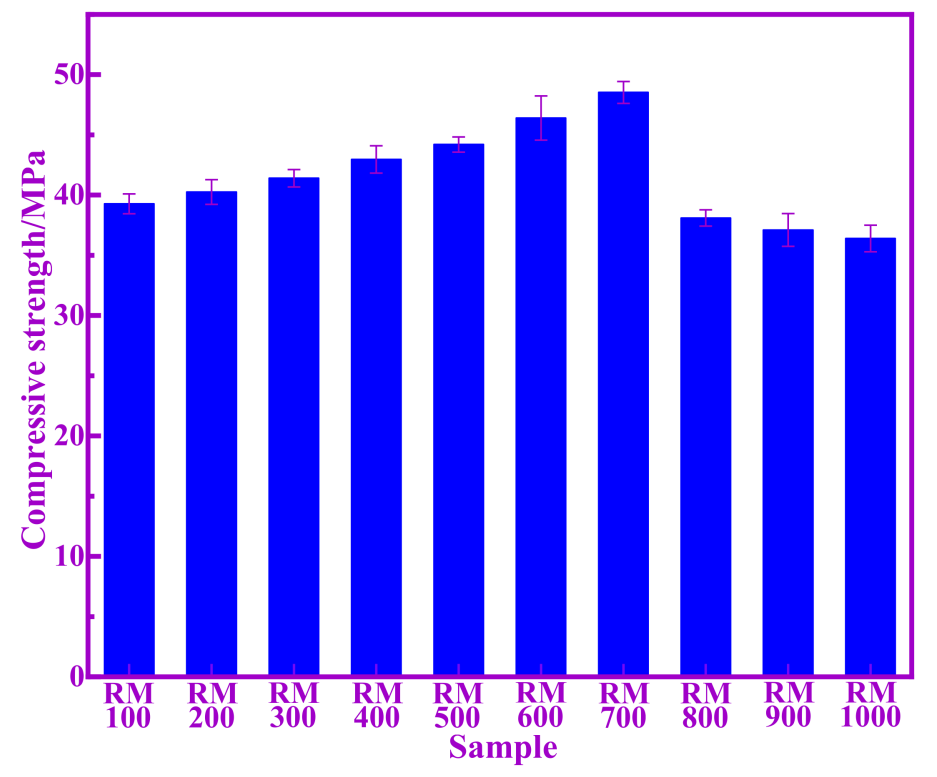

Figure 2. The compressive strength of samples at different temperatures.

Table 2. The pozzolanic activity index of calcined RM at different temperatures.

\begin{tabular}{ccccccccccc}
\hline Sample & RM100 & RM200 & RM300 & RM400 & RM500 & RM600 & RM700 & RM800 & RM900 & RM1000 \\
\hline $\mathrm{K} \alpha$ & $62.54 \%$ & $64.09 \%$ & $65.92 \%$ & $68.41 \%$ & $70.38 \%$ & $73.89 \%$ & $77.27 \%$ & $60.67 \%$ & $59.08 \%$ & $57.96 \%$ \\
\hline
\end{tabular}

\subsection{Pozzolanic Activity Evaluation for Dissolution of Silicon and Aluminum}

Active silicon and aluminum produced by the decomposition of pozzolanic materials are considered to be the main sources of pozzolanic activity $[20,21]$. Silicon and aluminum components that can be dissolved under alkaline conditions may participate in the hydration reaction of cement. Therefore, the higher the content of silicon and aluminum that can be dissolved in the RM, the higher the degree of the possible hydration reaction of the RM, and the more hydration products it produces [22]. For studying the dissolution amounts of silicon and aluminum in the active components of calcined RM in alkali solution, it is a more direct evaluation method to take the dissolution amount of silicon and aluminum in the solution as the index for evaluating the pozzolanic activity. Table 3 shows the dissolved concentrations of $\mathrm{Si}, \mathrm{Al}$ and $(\mathrm{Si}+\mathrm{Al})$ of $\mathrm{RM}$ at different temperatures in $\mathrm{NaOH}$ solution. It can be seen from Table 3 that the dissolution of active silicon and aluminum increases first and then decreases with the calcination temperature. The dissolution amounts of silicon and aluminum in RM700 are $85.47 \mathrm{mg} / \mathrm{L}$ and $121.30 \mathrm{mg} / \mathrm{L}$, respectively. The dissolution amounts of silicon and aluminum in RM1000 are $42.53 \mathrm{mg} / \mathrm{L}$ and $50.71 \mathrm{mg} / \mathrm{L}$, respectively. It is worth noting that the change trend for the dissolution amount of silicon and aluminum with temperature is consistent with that of the pozzolanic activity index. Therefore, the relationship between the pozzolanic activity index of RM and its dissolution amount of silicon and aluminum has been studied. The relationship between the pozzolanic activity index of RM and its dissolution concentration of $\mathrm{Si}$ is shown in Figure 3. The relationship between the pozzolanic activity index of RM and its dissolution concentration of $\mathrm{Al}$ is shown in Figure 4. The relationship between the pozzolanic activity index of RM and its dissolution concentration of ( $\mathrm{Si}+\mathrm{Al})$ is shown in Figure 5. It can be seen from Figures 3-5 that there is a good correlation between the dissolution concentration of $\mathrm{Si}, \mathrm{Al}$ and $(\mathrm{Si}+\mathrm{Al})$ in RM and its pozzolanic activity index, and there is a positive correlation (linear tendency) between them; the higher the dissolution concentration of $\mathrm{Si}, \mathrm{Al}$ and $(\mathrm{Si}+\mathrm{Al})$ is, the higher the pozzolanic activity index of RM is. The linear fitting $\mathrm{R}^{2}$ between pozzolanic activity of $\mathrm{RM}$ and dissolution concentration of $\mathrm{Si}, \mathrm{Al}$ and $(\mathrm{Si}+\mathrm{Al})$ is $0.92,0.95$ and 0.96 , respectively. It is worth noting that the linear fitting $\mathrm{R}^{2}$ between the dissolution concentration 
of $(\mathrm{Si}+\mathrm{Al})$ and the pozzolanic activity index is the largest, indicating that there is a good correlation between the pozzolanic activity of RM and the dissolution concentration of $(\mathrm{Si}+\mathrm{Al})$. Therefore, the dissolution amount of silicon and aluminum in RM is closely related to its pozzolanic activity.

Table 3. The dissolution concentration of $\mathrm{Si}$ and $\mathrm{Al}$ in calcined $\mathrm{RM}$ at different temperatures (mg/L).

\begin{tabular}{cccc}
\hline Sample & $\begin{array}{c}\text { Dissolution } \\
\text { Concentration of Si }\end{array}$ & $\begin{array}{c}\text { Dissolution } \\
\text { Concentration of Al }\end{array}$ & $\begin{array}{c}\text { Dissolution } \\
\text { Concentration of } \\
\text { (Si+Al) }\end{array}$ \\
\hline RM100 & 46.93 & 67.04 & 113.97 \\
RM200 & 47.18 & 67.44 & 114.62 \\
RM300 & 52.24 & 73.24 & 125.48 \\
RM400 & 54.73 & 92.51 & 147.24 \\
RM500 & 61.72 & 96.29 & 158.01 \\
RM600 & 75.25 & 120.60 & 195.85 \\
RM700 & 85.47 & 121.30 & 206.77 \\
RM800 & 45.63 & 64.60 & 110.23 \\
RM900 & 43.06 & 59.60 & 102.66 \\
RM1000 & 42.53 & 50.71 & 93.24 \\
\hline
\end{tabular}

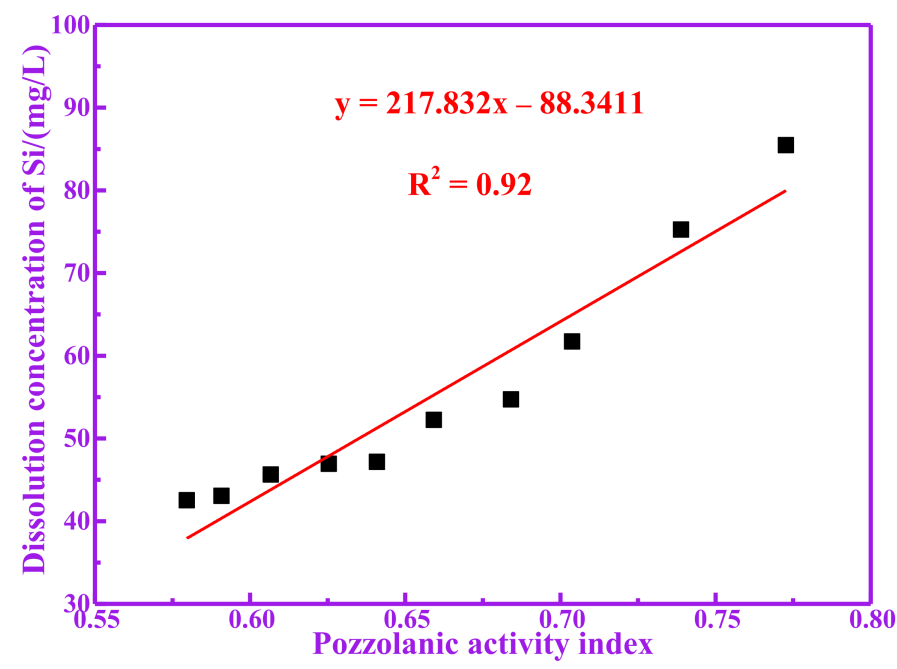

Figure 3. Correlation between dissolution concentration of Si and pozzolanic activity index.

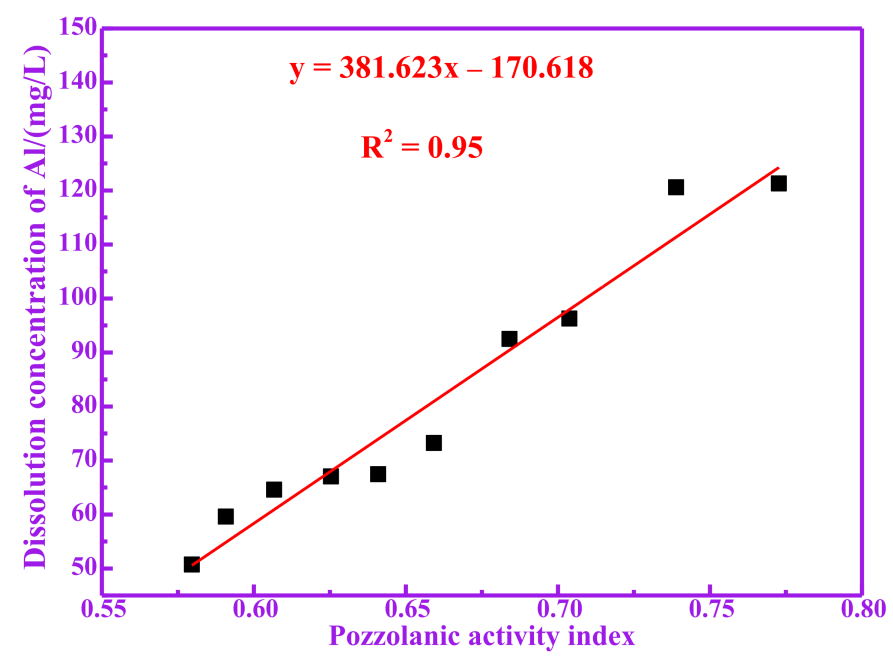

Figure 4. Correlation between dissolution concentration of $\mathrm{Al}$ and pozzolanic activity index. 


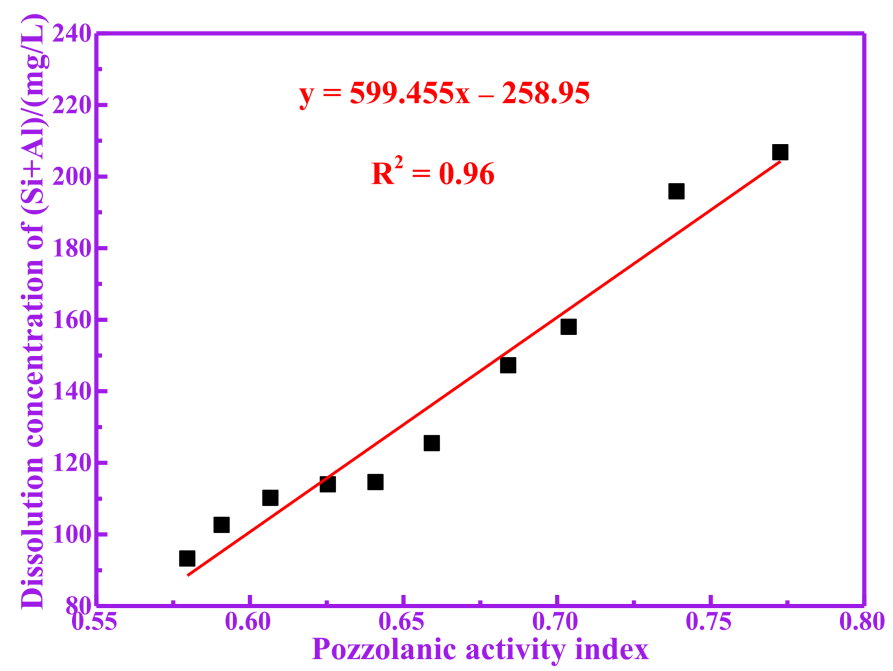

Figure 5. Correlation between dissolution concentration of $(\mathrm{Si}+\mathrm{Al})$ and pozzolanic activity index.

\subsection{Relationship between Polymerization Degree and Pozzolanic Activity for RM}

The chemical structural changes of RM calcined at different temperatures were analyzed by FTIR. Figure 6 shows the FTIR spectra of RM calcined at different temperatures. The absorption peak is $3638 \mathrm{~cm}^{-1}$, which corresponds to the stretching vibration of free $-\mathrm{OH}$ [3]. The absorption peak at $3452 \mathrm{~cm}^{-1}$ corresponds to the stretching vibration of associating - $\mathrm{OH}$. With increases in temperature, the free- $\mathrm{OH}$ in $\mathrm{RM}$ is gradually transformed into bound $-\mathrm{OH}$, which indicates that there is a certain amount of hydrogen bonding in its molecular structure. The absorption peaks of $1635 \mathrm{~cm}^{-1}$ and $1431 \mathrm{~cm}^{-1}$ correspond to the stretching vibration and antisymmetric stretching vibration of $\mathrm{C}-\mathrm{O}$, respectively. It can be seen from Figure 6 that the carbonate in RM gradually decomposes with increases in temperature. The absorption peak in the range of $800-1200 \mathrm{~cm}^{-1}$ is an asymmetric tensile vibration of $\mathrm{Si}-\mathrm{O}-\mathrm{Si}$ or $\mathrm{Si}-\mathrm{O}-\mathrm{Al}$ connected with a tetrahedron of $\left[\mathrm{SiO}_{4}\right]$ or $\left[\mathrm{AlO}_{4}\right]^{-}$[22]. The peak at $1092 \mathrm{~cm}^{-1}$ corresponds to the tensile vibration of $\mathrm{O}-\mathrm{Si}-(\mathrm{Si})$. The peak at $998 \mathrm{~cm}^{-1}$ is caused by the tensile vibration of Si-O (Al). The peak at $871 \mathrm{~cm}^{-1}$ corresponds to the tensile vibration of $\mathrm{Si}-\mathrm{O}-$. The absorption peak in the range of $600-800 \mathrm{~cm}^{-1}$ is symmetrical to stretching vibrations between $\mathrm{Si}-\mathrm{O}-(\mathrm{Si}, \mathrm{Al})$ in tetrahedrons of $\left[\mathrm{SiO}_{4}\right]$ or $\left[\mathrm{AlO}_{4}\right]^{-}$[23]. It can be seen from Figure 6 that the position and area of peaks in 800-1200 $\mathrm{cm}^{-1}$ changes with temperature, which indicates that the bond between $\mathrm{Si}, \mathrm{Al}$ and $\mathrm{O}$ in $\mathrm{RM}$ is broken or combined. The absorption peak of $582 \mathrm{~cm}^{-1}$ corresponds to the rings of $\mathrm{Si}-\mathrm{O}$ and $\mathrm{Al}-\mathrm{O}$. The peaks in the range of $400-500 \mathrm{~cm}^{-1}$ correspond to the bending vibration of $\mathrm{Si}-\mathrm{O}-\mathrm{Si}(\mathrm{Al})$.

The essence of pozzolanic materials participating in the hydration reaction of cement is the process of $\left[\mathrm{Si}(\mathrm{Al}) \mathrm{O}_{4}\right]$ tetrahedrons changing from their polymerization state, to their isolated state, back to their polymerization state; the increase in pozzolanic activity is caused by the depolymerization of polymerized $\left[\mathrm{Si}(\mathrm{Al}) \mathrm{O}_{4}\right]$ tetrahedrons (i.e., the fracture of the $\mathrm{Si}-\mathrm{O}-\mathrm{Si}(\mathrm{Al})$ bond). Generally, the smaller the polymerization degree of the silicon aluminum network is, the higher its pozzolanic activity is.

According to the number of coordination bridge oxygens around a Si, it can be divided into $\mathrm{SiQ}^{0}, \mathrm{SiQ}^{1}, \mathrm{SiQ}^{2}, \mathrm{SiQ}^{3}$ and $\mathrm{SiQ}^{4}$, where $\mathrm{n}$ in $\mathrm{SiQ}^{\mathrm{n}}$ represents the number of coordination bridge oxygens around $\mathrm{Si}$. The fracture of the $\mathrm{Si}-\mathrm{O}-\mathrm{Si}$ bond in $\left[\mathrm{SiO}_{4}\right]$ can cause changes in the $\mathrm{Si}$ coordination structure around bridge oxygens, that is, from $\mathrm{SiQ}^{\mathrm{n}}$ to $\mathrm{SiQ}^{\mathrm{n}-1}$. On the contrary, if $\mathrm{Si}-\mathrm{O}$ and $\mathrm{Si}-\mathrm{O}$ polymerize to form a $\mathrm{Si}-\mathrm{O}-\mathrm{Si}$ bond, the $\mathrm{Si}$ coordination structure around the bridge oxygens will change from $\mathrm{SiQ}^{\mathrm{n}}$ to $\mathrm{SiQ}^{\mathrm{n}+1}$. It is worth noting that the $\mathrm{Al}$ in the system can enter the $\left[\mathrm{SiO}_{4}\right]$ during the polymerization process to replace the $\mathrm{Si}$ and form $\left[\mathrm{AlO}_{4}\right]^{-}$, but it does not affect the change in the number of bridge oxygen bonds. Therefore, the change in bridge oxygen number can be used to reflect the relative degree of polymerization or depolymerization in the system. Zhang et al. [17]. proposed the concept 
of $\mathrm{RBO}$ to evaluate the polymerization degree of $\left[\mathrm{SiO}_{4}\right]$. Therefore, here the authors used the polymerization degree to reflect the pozzolanic activity of calcined RM at different temperatures. In FTIR spectra, the characteristic peaks of $\mathrm{SiQ}^{0}, \mathrm{SiQ}^{1}, \mathrm{SiQ}^{2}, \mathrm{SiQ}^{3}$, and $\mathrm{SiQ}^{4}$ are about $850 \mathrm{~cm}^{-1}, 950 \mathrm{~cm}^{-1}, 1000 \mathrm{~cm}^{-1}, 1050 \mathrm{~cm}^{-1}$, and $1100 \mathrm{~cm}^{-1}$, respectively. Origin software was used to separate and fit peaks between $800-1200 \mathrm{~cm}^{-1}$, whereas the peak area and RBO were calculated. Figure 7 shows the peaks in the range of $800-1200 \mathrm{~cm}^{-1}$ of the FTIR spectra of calcined RM at different temperatures. Table 4 shows the relevant parameters of the peaks of calcined RM at different temperatures. It can be seen from Table 4 that the polymerization degree of RM first decreases and then increases with the increase in temperature. The high polymerization degree indicates that the silicon and aluminum component has stable chemical properties. The low polymerization degree indicates that the $\mathrm{Si}-\mathrm{O}-\mathrm{Si}(\mathrm{Al})$ bond in the RM is destroyed, which will increase the active silicon and aluminum in the RM.

Figure $8 \mathrm{a}-\mathrm{c}$ show the relationship between $\mathrm{RBO}$ and dissolution concentration of $\mathrm{Si}, \mathrm{Al}$ and $(\mathrm{Si}+\mathrm{Al})$ of calcined $\mathrm{RM}$ at different temperatures, respectively. It can be seen from Figure $8 \mathrm{a}-\mathrm{c}$ that RBO tends to be linear to the dissolution concentration of $\mathrm{Si}, \mathrm{Al}$ and $(\mathrm{Si}+\mathrm{Al})$, respectively. Therefore, the lower the RBO of RM is, the higher the dissolution concentration of $\mathrm{Si}, \mathrm{Al}$ and $(\mathrm{Si}+\mathrm{Al})$ is. Therefore, the decrease in $\mathrm{RBO}$ promoted an increase of the dissolution concentration of $\mathrm{Si}, \mathrm{Al}$ and $(\mathrm{Si}+\mathrm{Al})$ in $\mathrm{RM}$. According to the results of the $\mathrm{XRD}$, this behavior is due to the conversion of crystalline phase substances in the RM into active $\mathrm{Si}$ and $\mathrm{Al}$ at $700{ }^{\circ} \mathrm{C}$, resulting in the increase in the dissolution concentration of $\mathrm{Si}, \mathrm{Al}$ and $(\mathrm{Si}+\mathrm{Al})$.

Figure 9 shows the relationship between RBO and pozzolanic activity of calcined RM at different temperatures. It can be seen from Figure 9 that there is a significant correlation between the pozzolanic activity of RM and its RBO. Therefore, the trend of this relationship is that the smaller the RBO of RM, the higher the pozzolanic activity that is obtained by RM. Therefore, compared with the compressive strength and dissolution of silicon and aluminum, the polymerization degree evaluation method of pozzolanic activity is simple and fast. At the same time, the method also obtains similar results. The most important thing is that the proposed method is adequate to verify the pozzolanic activity of RM.

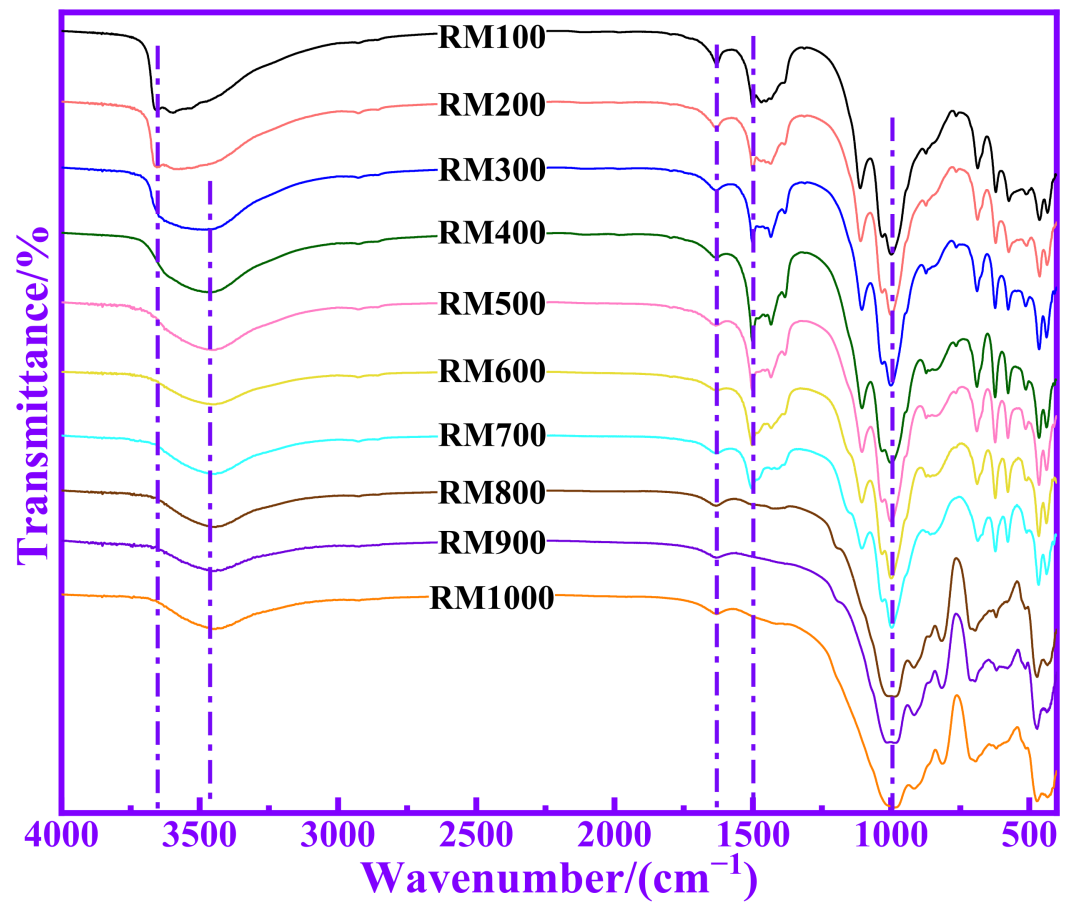

Figure 6. The FTIR spectrum of calcined RM at different temperatures. 

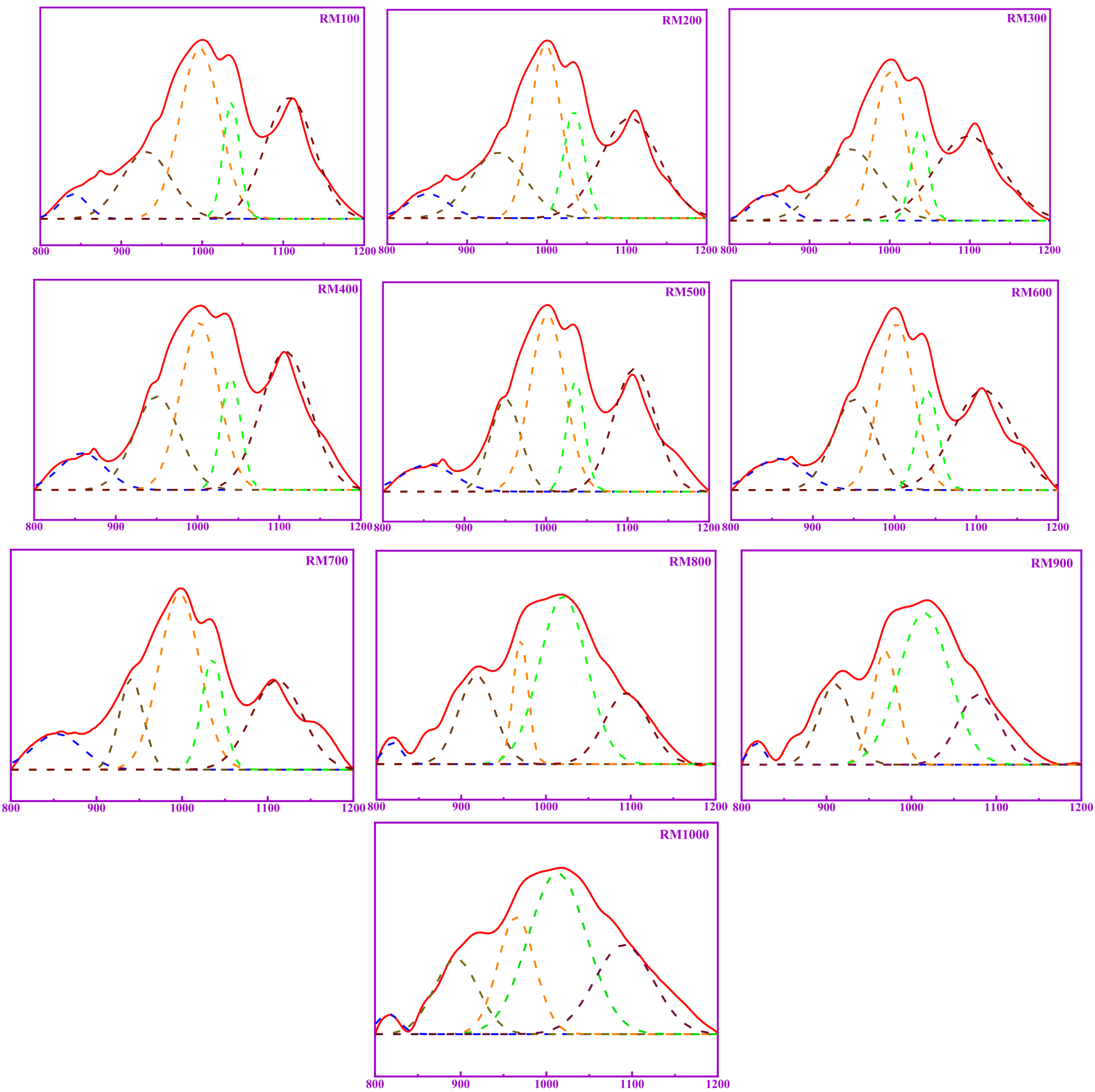

Figure 7. The peaks in the range of $800-1200 \mathrm{~cm}^{-1}$ of calcined RM at different temperatures.

Table 4. The relevant parameters of the peaks of calcined RM at different temperatures.

\begin{tabular}{cccccccc}
\hline \multirow{2}{*}{ Sample } & \multicolumn{9}{c}{ Relative Content/\% } & \multirow{2}{*}{ RBO } & \multirow{2}{*}{$\mathbf{R}^{\mathbf{2}}$} \\
\cline { 2 - 5 } & $\mathbf{S i Q}^{\mathbf{0}}$ & $\mathbf{S i Q}^{\mathbf{1}}$ & $\mathbf{S i Q}^{\mathbf{2}}$ & $\mathbf{S i Q}^{\mathbf{3}}$ & $\mathbf{S i Q}^{\mathbf{4}}$ & & \\
\hline RM100 & 3.20 & 17.21 & 35.12 & 10.95 & 33.52 & 0.6360 & 0.995 \\
RM200 & 4.41 & 20.11 & 30.04 & 12.42 & 33.02 & 0.6238 & 0.995 \\
RM300 & 5.43 & 24.20 & 27.24 & 9.26 & 33.87 & 0.6049 & 0.995 \\
RM400 & 7.85 & 19.87 & 29.98 & 10.38 & 31.92 & 0.5966 & 0.995 \\
RM500 & 8.07 & 15.98 & 35.40 & 11.22 & 29.33 & 0.5944 & 0.994 \\
RM600 & 8.28 & 19.21 & 30.30 & 11.07 & 31.14 & 0.5939 & 0.994 \\
RM700 & 9.74 & 12.05 & 39.65 & 13.29 & 25.27 & 0.5808 & 0.987 \\
RM800 & 2.13 & 19.39 & 11.39 & 48.13 & 18.96 & 0.6560 & 0.992 \\
RM900 & 2.07 & 15.83 & 17.03 & 46.56 & 18.51 & 0.6590 & 0.995 \\
RM1000 & 1.93 & 14.75 & 19.23 & 41.39 & 22.7 & 0.6705 & 0.988 \\
\hline
\end{tabular}




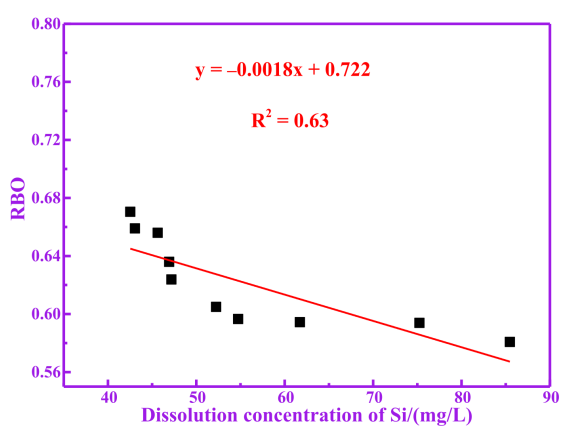

(a)

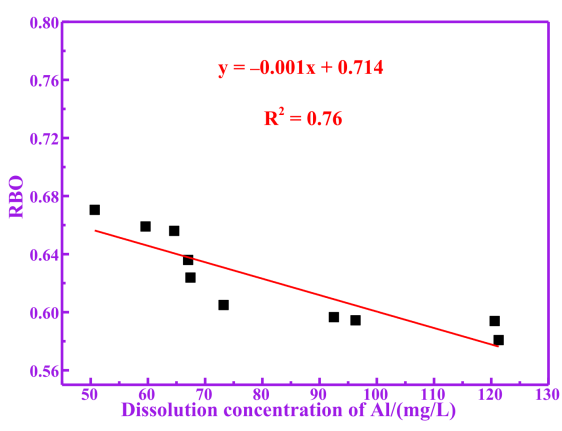

(b)

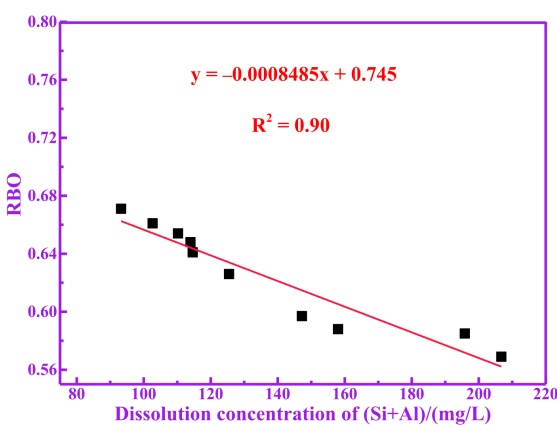

(c)

Figure 8. Correlation between dissolution concentration of ( $\mathrm{Si}+\mathrm{Al})$ and $\mathrm{RBO}$. (a) $\mathrm{Si}$; (b) $\mathrm{Al}$; (c) (Si+Al).

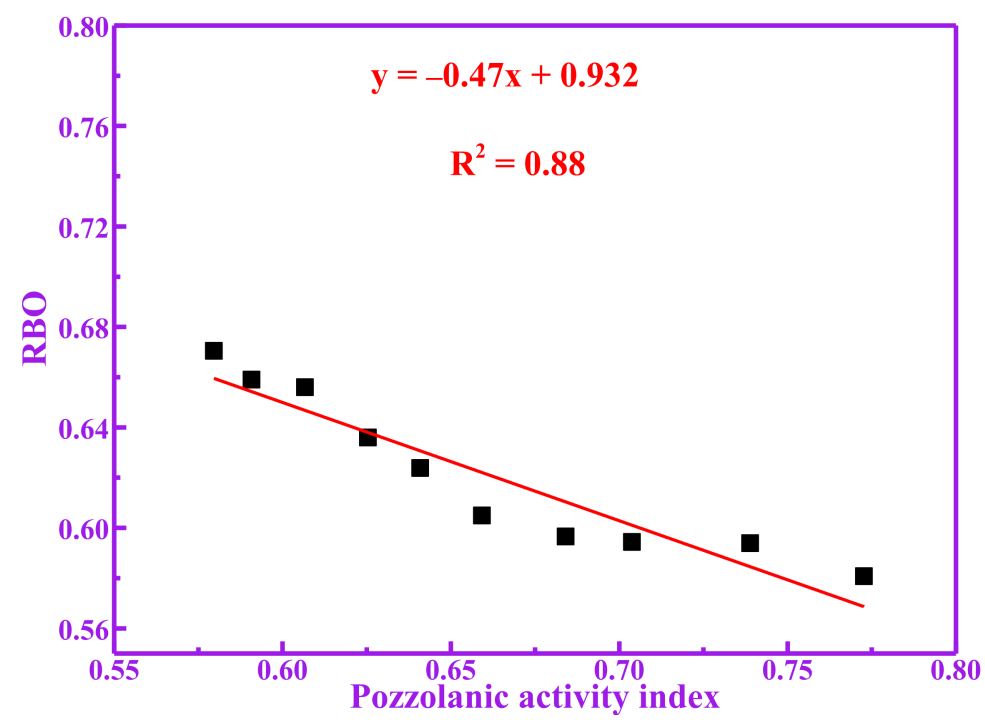

Figure 9. Correlation between $\mathrm{RBO}$ and pozzolanic activity index.

\section{Conclusions}

In this work, a new method to evaluate the pozzolanic activity of RM by its polymerization degree was proposed. The relationships between compressive strength, dissolution concentration of $(\mathrm{Si}+\mathrm{Al})$ and polymerization degree method with pozzolanic activity of RM were studied, respectively. A correlation between polymerization degree method, compressive strength and dissolution concentration of ( $\mathrm{Si}+\mathrm{Al})$ was established. The main findings of this work are as follows:

The pozzolanic activity of RM can be calculated quantitatively by polymerization degree method and compressive strength and dissolution concentration of ( $\mathrm{Si}+\mathrm{Al})$. The polymerization degree of RM had a good linear relationship with the pozzolanic activity index, obtained by the strength index and dissolution concentration of ( $\mathrm{Si}+\mathrm{Al})$, respectively.

The polymerization degree of RM decreases with increases in pozzolanic activity, which is negatively correlated. The compressive strength and dissolution concentration of $(\mathrm{Si}+\mathrm{Al})$ are positively correlated with the pozzolanic activity of RM. The fitting equation between the polymerization degree and the pozzolanic activity index of RM was $y=-0.47 x+0.932$, where $R^{2}$ was 0.88 . The fitting equation between the polymerization degree and the dissolution concentration of $(\mathrm{Si}+\mathrm{Al})$ of $\mathrm{RM}$ was $\mathrm{y}=-0.0008485 \mathrm{x}+0.745$, where $\mathrm{R}^{2}$ was 0.90 .

Compared to the compressive strength, with a test cycle of 28 days, and the dissolution of $(\mathrm{Si}+\mathrm{Al})$, with a test cycle of 7 days, the polymerization degree method has the advantages of a short test cycle, convenience and low cost. It is related to the structure of silicon and aluminum in RM and is not easily affected by the test environment. Therefore, it is a fast, 
simple and reliable method to evaluate the pozzolanic activity of RM by polymerization degree method.

Through research on the relationship between the polymerization degree of RM and its pozzolanic activity, a linear relationship between them was found. However, this work only studied one industrial solid waste-RM. From the results of this work, the polymerization degree method may be applicable to the pozzolanic activity evaluation of many kinds of industrial solid wastes. In the future, the authors will try to apply this method to other solid wastes other than RM. In conclusion, this work provides a reference for the study of fast and reliable evaluation methods of pozzolanic activity of industrial solid waste in the future.

Author Contributions: Conceived and designed the analysis, collected the data, contributed data or analysis tools, performed the analysis, wrote the paper, Y.W.; conceived and designed the analysis, collected the data, contributed data or analysis tools, performed the analysis, wrote the paper, X.L.; contributed data or analysis tools, performed the analysis, wrote the paper, Z.X.; contributed data or analysis tools, performed the analysis, H.W.; contributed data or analysis tools, performed the analysis, wrote the paper, W.Z.; contributed data or analysis tools, performed the analysis, wrote the paper, Y.X. All authors have read and agreed to the published version of the manuscript.

Funding: This research was funded by the National Natural Science Foundation of China, project number 52074035, and Fundamental Research Funds for the Central Universities, project number FRF-AT-20-08.

Institutional Review Board Statement: Not applicable.

Informed Consent Statement: Not applicable.

Data Availability Statement: Data sharing is not applicable to this article.

Conflicts of Interest: The authors declare no conflict of interest.

\section{References}

1. Wang, C.; Zhang, X.; Sun, R.; Cao, Y. Neutralization of red mud using bio-acid generated by hydrothermal carbonization of waste biomass for potential soil application. J. Clean. Prod. 2020, 271, 122525. [CrossRef]

2. Wang, Y.; Li, D.; Liu, X.; Zhang, W.; Li, Z.; Li, Y.; Ren, Y.; Li, H. Mechanism of magnetizing the Bayer red mud and meanwhile improving the cementitious activity of its tailings by using biomass. J. Clean. Prod. 2021, 287, 125016. [CrossRef]

3. Wang, Y.; Liu, X.; Li, Y.; Zhang, W.; Xue, Y. Tailings after Iron Extraction in Bayer Red Mud by Biomass Reduction: Pozzolanic Activity and Hydration Characteristics. Materials 2021, 14, 3955. [CrossRef]

4. Cho, Y.K.; Jung, S.H.; Choi, Y.C. Effects of chemical composition of fly ash on compressive strength of fly ash cement mortar. Constr. Build. Mater. 2019, 204, 255-264. [CrossRef]

5. Peng, D.; Wang, Y.; Liu, X.; Tang, B.; Zhang, N. Preparation, characterization, and application of an eco-friendly sand-fixing material largely utilizing coal-based solid waste. J. Hazard. Mater. 2019, 373, 294-302. [CrossRef] [PubMed]

6. Liu, J.; Yu, B.; Wang, Q. Application of steel slag in cement treated aggregate base course. J. Clean. Prod. 2020, 269, 121733. [CrossRef]

7. Ortega, J.M.; Cabeza, M.; Tenza-Abril, A.J.; Real-Herraiz, T.; Climent, M.; Sánchez, I. Effects of red mud addition in the microstructure, durability and mechanical performance of cement mortars. Appl. Sci. 2019, 9, 984. [CrossRef]

8. Payá, J.; Borrachero, M.V.; Monzó, J.; Peris-Mora, E.; Amahjour, F. Enhanced conductivity measurement techniques for evaluation of fly ash pozzolanic activity. Cem. Concr. Res. 2001, 31, 41-49. [CrossRef]

9. Tashiro, C.; Ikeda, K.; Inoue, Y. Evaluation of pozzolanic activity by the electric resistance measurement method. Cem. Concr. Res. 1994, 24, 1133-1139. [CrossRef]

10. Roszczynialski, W. Determination of pozzolanic activity of materials by thermal analysis. J. Therm. Anal. Calorim. 2002, 70, 387-392. [CrossRef]

11. Shvarzman, A.; Kovler, K.; Schamban, I.; Grader, G.S.; Shter, G.E. Influence of chemical and phase composition of mineral admixtures on their pozzolanic activity. Adv. Cem. Res. 2002, 14, 35-41. [CrossRef]

12. Feng, Y.; Yang, Q.; Chen, Q.; Kero, J.; Andersson, A.; Ahmed, H.; Engström, F.; Samuelsson, C. Characterization and evaluation of the pozzolanic activity of granulated copper slag modified with CaO. J. Clean. Prod. 2019, 232, 1112-1120. [CrossRef]

13. Martín, C.M.; Scarponi, N.B.; Villagrán, Y.A.; Manzanal, D.G.; Piqué, T.M. Pozzolanic activity quantification of hollow glass microspheres. Cem. Concr. Compos. 2021, 118, 103981. [CrossRef]

14. Basto, P.A.; Junior, H.; Neto, A.A. Characterization and pozzolanic properties of sewage sludge ashes (SSA) by electrical conductivity. Cem. Concr. Compos. 2019, 104, 103410. [CrossRef] 
15. Hasani, M.; Tarighat, A. Proposing new pozzolanic activity index based on water adsorption energy via molecular dynamics simulations. Constr. Build. Mater. 2019, 213, 492-504. [CrossRef]

16. Supervision, T. Pozzolanic Materials Used for Cement Production, in Chinese Code GB/T 2847-2005; Chinese Standard Press: Beijing, China, 2005.

17. Zhang, J.-X.; Sun, H.-H.; Sun, Y.-M.; Zhang, N. Correlation between 29 Si polymerization and cementitious activity of coal gangue. J. Zhejiang Univ.-Sci. A 2009, 10, 1334-1340. [CrossRef]

18. Zhang, J.X.; Sun, H.H.; Wan, J.H.; Zhang, N. Si polymerization degree of hydrates in coal gangue added cement. J. Cent. South Univ. Sci. Technol. 2011, 42, 329-335.

19. Liu, X.; Zhang, N.; Sun, H.; Zhang, J.; Li, L. Structural investigation relating to the cementitious activity of bauxite residue-Red mud. Cem. Concr. Res. 2011, 41,847-853. [CrossRef]

20. Zhou, M.; Chen, P.; Chen, X.; Ge, X.; Wang, Y. Study on hydration characteristics of circulating fluidized bed combustion fly ash (CFBCA). Constr. Build. Mater. 2020, 251, 118993. [CrossRef]

21. Wang, Y.; Liu, X.; Zhang, W.; Li, Z.; Zhang, Y.; Li, Y.; Ren, Y. Effects of Si / Al ratio on the efflorescence and properties of fly ash based geopolymer. J. Clean. Prod. 2020, 244, 118852. [CrossRef]

22. Wang, Q.; Wang, D.; Zhuang, S. The soundness of steel slag with different free $\mathrm{CaO}$ and $\mathrm{MgO}$ contents. Constr. Build. Mater. 2017, 151, 138-146. [CrossRef]

23. Zhang, Y.; Liu, X.; Xu, Y.; Tang, B.; Wang, Y.; Mukiza, E. Preparation and characterization of cement treated road base material utilizing electrolytic manganese residue. J. Clean. Prod. 2019, 232, 980-992. [CrossRef] 